\title{
คteknokultura
}

\#López Gabrielidis, A. (2015). Régimen de visibilidad y vigilancia en la era de la Identidad Digital. Revista Teknokultura, Vol. 12(3), 473-499.

Recibido: $30-09-2015$

Aceptado: 06-11-2015
Open peer review

http://revistas.ucm.es/index.php/TEKN/pages/view/opr-50385

\section{Régimen de visibilidad $y$ vigilancia en la era de la Identidad Digital}

\author{
Visibility and surveillance regime \\ in the age of Digital Identity
}

Alejandra López Gabrielidis

Universidad de Barcelona - Universidad Rennes 2 cleonike@gmail.com

\section{Resumen}

Este artículo aborda el vínculo entre el régimen de hipervisiblidad en el que se halla inscripto el sujeto contemporáneo y las nuevas formas de vigilancia. A partir de un análisis de la obra audiovisual de Hito Steyerl "How Not to be Seen: A Fucking Didactic Educational.MOV File" (2013) se exploran las modificaciones que ha sufrido el modelo de vigilancia tradicional y se destacan las características que reviste el dispositivo de cibervigilancia actual. El s. XXI está siendo testigo del fenómeno socio-técnico de transformación del sujeto en imagen-dato como fruto de lo que Paul Virilio denomina la industrialización y proliferación de las "máquinas de visión" (cámaras fotográficas, microscopios, telescopios, drones), de los hábitos sociales en línea que tienden a la autocaptación y autodifusión, y de los procesos de 
datificación. El sujeto asume hoy en día un rol activo en los mecanismos de vigilancia y por lo tanto es corresponsable del control que se ejerce sobre él. En este vídeo, Hito Steyerl nos enseña técnicas de camuflaje, confusión y de usos de la baja resolución para poder ser más invisibles ante los ojos del poder. Sin embargo, el exceso de visibilidad y exposición del sujeto parece ser una circunstancia difícil de contrarrestar en las condiciones técnicas en las que vivimos. Como reflexionamos hacia el final del artículo, para resolver los problemas de vigilancia en la era digital es preciso redefinir la noción de privacidad a partir del concepto de identidad digital, con todo lo que ello implica, y abrir así el camino hacia nuevas formas de data potestad.

\section{Palabras Clave}

Máquinas de visión; hipervisibilidad; ciber-vigilancia; privacidad; data potestad.

\section{Abstract}

This article addresses the link between the hypervisibility regime in which the contemporary subject is immersed in and the new forms of surveillance. Based on an analysis of the work of Hito Steyerl "How Not to be Seen: A Fucking Didactic Educational .MOV File" (2013) we explore the changes suffered by the traditional form of surveillance with a special highlight on the current features of the cyber-surveillance device. The 21 st century is witnessing a socio-technical phenomenon which transforms the subject into an image-data, as a result of what Paul Virilio calls the industrialization and proliferation of "visual machines" (photographic cameras, microscopes, telescopes, drones), the social online habits which tend to self-capture and self-diffusion, and the processes of datification. Nowadays, the subject assumes an active role in the surveillance mechanisms and, hence, is partly responsible of the control that is practiced over him. In this video, Hito Steyerl teaches us about camouflage techniques, confusion and low resolution uses, in order to be less visible before the eyes of the power. However, the excess of visibility and exposure of the subject seems to be a highly difficult situation to counteract in the technical conditions that we live in. As we propose in the last section of the article, in order to solve the surveillance problems in the digital age it is necessary to redefine the concept of privacy starting from the concept of digital identity, with all its implications. Consequently, we must lead the way into new forms of legal authority over data. 


\section{KeYWORDS}

Vision machines; hypervisibility; cyber-surveillance; privacy; data legal authority.

\section{Sumario}

El fenómeno socio-técnico de transformación del sujeto en imagen-dato

La resolución de la identidad digital

El punto de vista aéreo del poder. Posición desventajosa del sujeto vigilado

La fuente de las imágenes de vigilancia. Posición ventajosa del sujeto vigilado

Lecciones de invisibilidad

Las nuevas modalidades de vigilancia

Actualización de la noción de "privacidad"

La identidad digital y la I-Data potestad

Referencias

\section{SUMmaRY}

The sociotechnic phenomenon of the subject's transformation into an image

The subject becoming visible and measurable in terms of resolution

The aerial point of view of power. Disadvantaged position of the surveil subject

The source of the surveillance images. Advantageous position of the surveil subject

Invisibility lessons

The new forms of surveillance

The "privacy" concept updated

The digital identity and the I-Data legal authority

References 


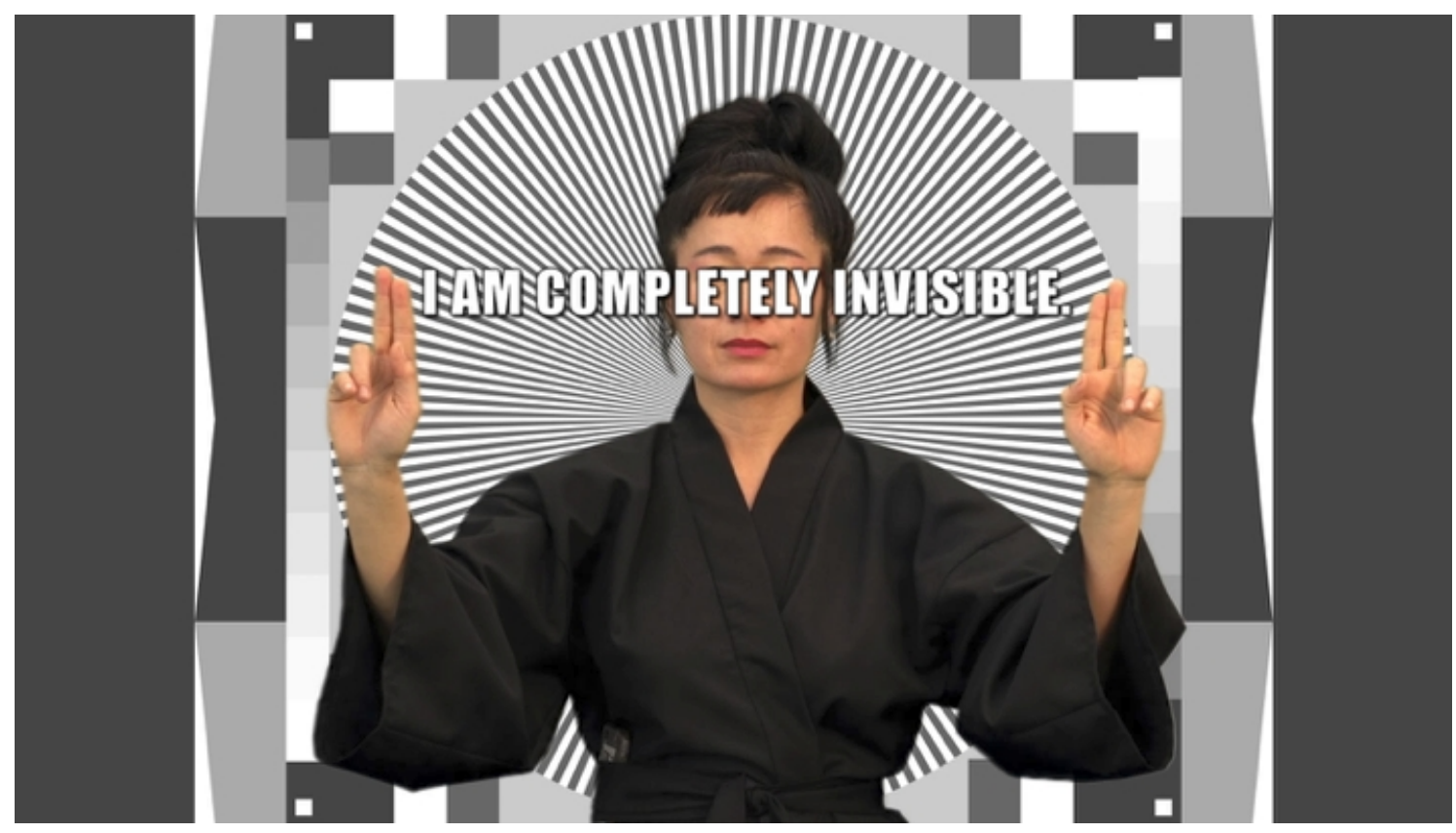

Captura de pantalla del vídeo How Not to be Seen: A Fucking Didactic Educational.MOV File (Steyerl, 2013).

Fuente: DIS Magazine (2015) <http://dismagazine.com/disillusioned-2/62143/hito-steyerl-politics-of-postrepresentation/>.

How Not to be Seen: A Fucking Didactic Educational.MOV File es un vídeo en alta definición de una duración de 14 minutos que fue expuesto por primera vez en 2013 en la Bienal de Venecia.

El vídeo está compuesto de imágenes filmadas y de animaciones 3D. La artista eligió como localización un antiguo terreno militar situado en el desierto de California. Este emplazamiento presenta un tramado en el suelo que servía, en la época de la fotografía analógica, como target de resolución para calibrar cámaras fotográficas de espionaje aéreo. Desde la llegada de la fotografía digital, este target ha quedado en desuso y abandonado, dejando el tramado del suelo agrietado por los efectos del tiempo. En lo que concierne a las partes de 
animación 3D se trata de renders de tipo arquitectónico en las que la cámara se pasea por el exterior y el interior de un edificio y un centro comercial con siluetas humanas que recorren dichos emplazamientos.

Durante el desarrollo del vídeo una voz en off masculina da, de forma pedagógica, una serie de instrucciones acerca de cómo lograr ser invisible en la era de la proliferación de la imagen. Se trata de una voz casi mecánica y sintética que nos da la sensación de un narrador impersonal. Mientras las instrucciones son enunciadas, una por una, la artista y un grupo de personas las ilustran y ejemplifican.

Podríamos calificar estas instrucciones de "tácticas", en el sentido de Michel De Certeau, para aprender a manejar nuestra visibilidad. Según dicho autor:

Las tácticas son procedimientos valiosos en función de la pertinencia con la que actúen en el tiempo - en las circunstancias en las que el instante preciso de una intervención transforma una situación en favorable, en la rapidez de los movimientos que cambian la organización del espacio, en las relaciones entre un "golpe" y momentos sucesivos, en los posibles cruces entre duraciones y ritmos heterogéneos, etc. ${ }^{1}$

(De Certeau, 1990, p. 62).

En esta obra Hito Steyerl parece sugerirnos que nos encontramos acechados por nuestras propias imágenes, ya que ellas abren la puerta a una mirada intrusiva que le permite al poder económico y político, vigilarnos y controlarnos. Este vídeo detecta un estado de fatiga generado por la superproducción de imágenes y datos personales, un sentimiento de impotencia frente a la vigilancia que ello conlleva y una necesidad de alivio a través de la invisibilidad.

\footnotetext{
${ }^{1}$ Trad. personal. Texto original: "Les tactiques sont des procédures qui valent par la pertinence qu'elles donnent au temps - aux circonstances que l'instant précis d'une intervention transforme en situation favorable, à la rapidité de mouvements qui change l'organisation de l'espace, aux relations entre moments successifs d'un « coup », aux croisements possibles de durées et de rythmes hétérogènes, etc."
} 


\section{El fenómeno sociotécnico de transformación del sujeto en imagen-dato}

Paul Virilo, en su libro Máquinas de visión (1988), explica la separación y el desdoblamiento del punto de vista que se produce entre la formación de imágenes mentales obtenidas de una percepción orgánica y directa y las imágenes mentales obtenidas por medio de máquinas que actúan como prótesis de visión (cámara fotográfica, grabadora, telescopio, microscopio, satélites, drones, etc). La visión de estas máquinas desliga la representación que nos hacemos del mundo del área de visión que está al alcance de nuestro cuerpo.

Con la industrialización y proliferación de estas prótesis de visión asistimos a un desplazamiento del lugar de construcción de las imágenes mentales, pues las engendramos a través de un punto de vista que no es el nuestro, sino aquél del objeto técnico. Esto significa que la condición de presencia conjunta del que ve y lo que ve queda suprimida. El cuerpo se encuentra cada vez menos solicitado, nuestro acercamiento al mundo ya no se produce necesariamente desde nuestra presencia física, sino desde una teletopología. Es decir, desde una aprehensión a distancia del espacio.

Sumado a la proliferación de las máquinas de visión, asistimos en el siglo XXI a un fenó meno de "datificación". ${ }^{2}$ Este término no es equivalente con el de digitalización, ésta última es un proceso de traducción de la realidad a un lenguaje binario. La datificación es un fenómeno ligado directamente al Big Data e implica, no sólo la traducción de la realidad a un lenguaje binario, sino también su integración en enormes bases de datos. Una vez allí, los sistemas de procesamiento permiten que la información sea conectada, analizada, catalogada, manipulada al formar parte de dinámicas algorítmicas complejas como, por ejemplo, los modelos predictivos. En este sentido, la imagen de un árbol que muestra una fotografía digital, en cuanto pura información visual, se corresponde con un fenómeno de digitalización del árbol. Los metadatos, que nos informan acerca del lugar donde se tomó la fotografía, el día, la hora, la cámara que se utilizó, etc., se corresponden con el fenómeno de datificación.

Los objetos que estructuran nuestra realidad ya no son inanimados, funcionales, decorativos, mobiliarios o incluso mecánicos; hoy son objetos de visión, inteligentes, informatizados y están provistos de una enorme cantidad de sensores. Ellos pueblan cada vez más nuestro en -

\footnotetext{
2 Neologismo que forma parte de nuestra investigación doctoral en curso: "La datificación: estudio acerca de prácticas y experimentaciones artísticas en torno al desdoblamiento digital del sujeto", dirigido por Nicolas Thély y Antonia Vilà en cotutela entre la Universidad Rennes 2 y la Universidad de Barcelona.
} 
torno cotidiano, y en consecuencia, las ocasiones de captación óptico-técnica del sujeto se multiplican.

Hito Steyerl nos remite a este proceso de cambio en la representación mental producido por la multiplicación de formas de producción automáticas y mecánicas de la imagen de la que habla Paul Virilo y a la sobreexposición a la que nos confina la datificación. Esta obra subraya el hecho de que nos encontramos rodeados de "objetos que nos miran" cada vez más pe queños, portátiles y eficaces. Habitamos en un régimen de visibilidad que se intensifica y que nos desborda, un régimen en el que es el mundo de los objetos, y no nuestro cuerpo, el que nos hace acercarnos y percibir el mundo.

\section{Figura 2: TRANSFORMAR EL MUNDO EN IMAGEN}

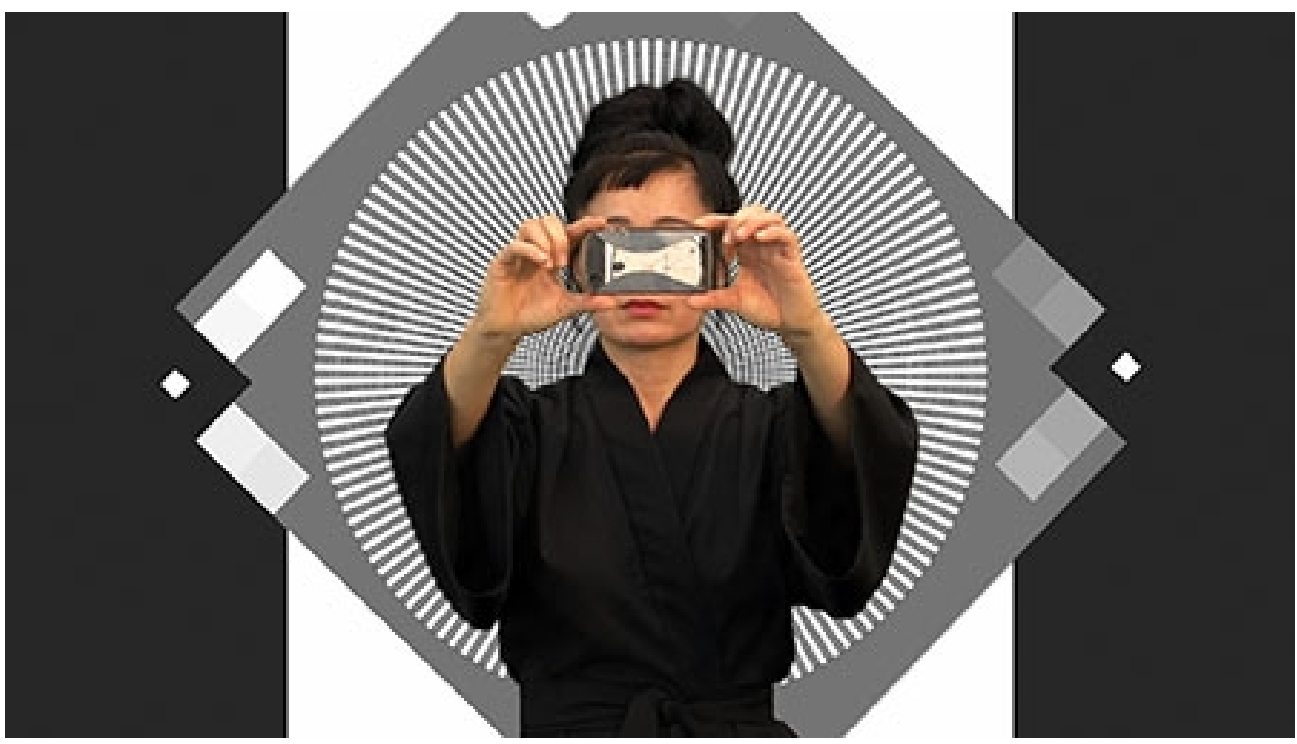

Captura de pantalla del vídeo How Not to be Seen: A Fucking Didactic Educational.MOV File (Steyerl, 2013).

Fuente: Frieze Magazine (2013) <http://www.frieze.com/issue/article/the-film-essay/>.

A estas condiciones de orden técnico respecto a la hipervisibilidad se suma una condición de orden social. En efecto, existe una suerte de exigencia impuesta por los diseños y usos de las redes sociales, que empuja al individuo a reducir su presencia a imagen, a autocaptarse (selfies) y captar su entorno próximo, a exteriorizar constantemente sus pensamientos, inclinaciones políticas, gustos musicales y compartirlo en línea. El régimen de inscripción subjetiva online se efectúa mediante un proceso de transformación del sujeto en imagen-dato. No 
se trata únicamente de un fenómeno que se limite a las generaciones jóvenes o a las redes sociales como Facebook, hoy en día incluso ciertas universidades, hospitales y centros de investigación demandan a sus empleados incluir una foto en sus páginas webs. El individuo y su identidad se simplifican, en gran medida, a su representación visual.

En efecto, la única manera de distribuir la presencia del sujeto en la red y hacerlo ubicuo, es a condición de reducir su presencia física a imagen, texto o sonido. Para poder distribuirse en numerosas direcciones al unísono es necesario que el cuerpo sea codificado.

Hito Steyerl nos habla en esta obra del sujeto y del mundo en tanto imagen-dato y nos pone de manifiesto que la identidad digital implica un exceso de visibilidad que nos hace vul nerables. La artista se propone, entonces, instruirnos sobre los diferentes modos de devenir "invisibles", de escapar y tergiversar la exigencia de visibilidad que favorece la vigilancia.

\section{La resolución de la identidad digital}

En la primera de sus lecciones la artista afirma que el target de resolución, refiriéndose al target de California, mide la visibilidad del mundo en tanto imagen. En efecto, el mundo que habita en los objetos digitales, el mundo que nos llega a través de imágenes satelitales o google street, es un mundo datificado. La reducción de la realidad a imagen-dato posibilita que esta pueda ser medida, controlada y vigilada. Se trata de un proceso similar a lo que sucede cada vez que una fuerza física se transforma en una ecuación para un científico. En la era digital, el sujeto y el mundo traducidos a datos están hechos de ceros y unos y son programables.

El sujeto, que forma parte de las cosas físicas del mundo, deviene él también un objeto de bido a una excesiva captación óptico/técnica cada vez más perfeccionada. Estamos en la época de la "alta resolución". En tanto imagen que circula por la web y que posee su soporte de presencia en los objetos técnicos, la identidad digital es mensurable en términos de "resolución". Es decir, susceptible de ser vista y analizada en mayor o menor detalle. 


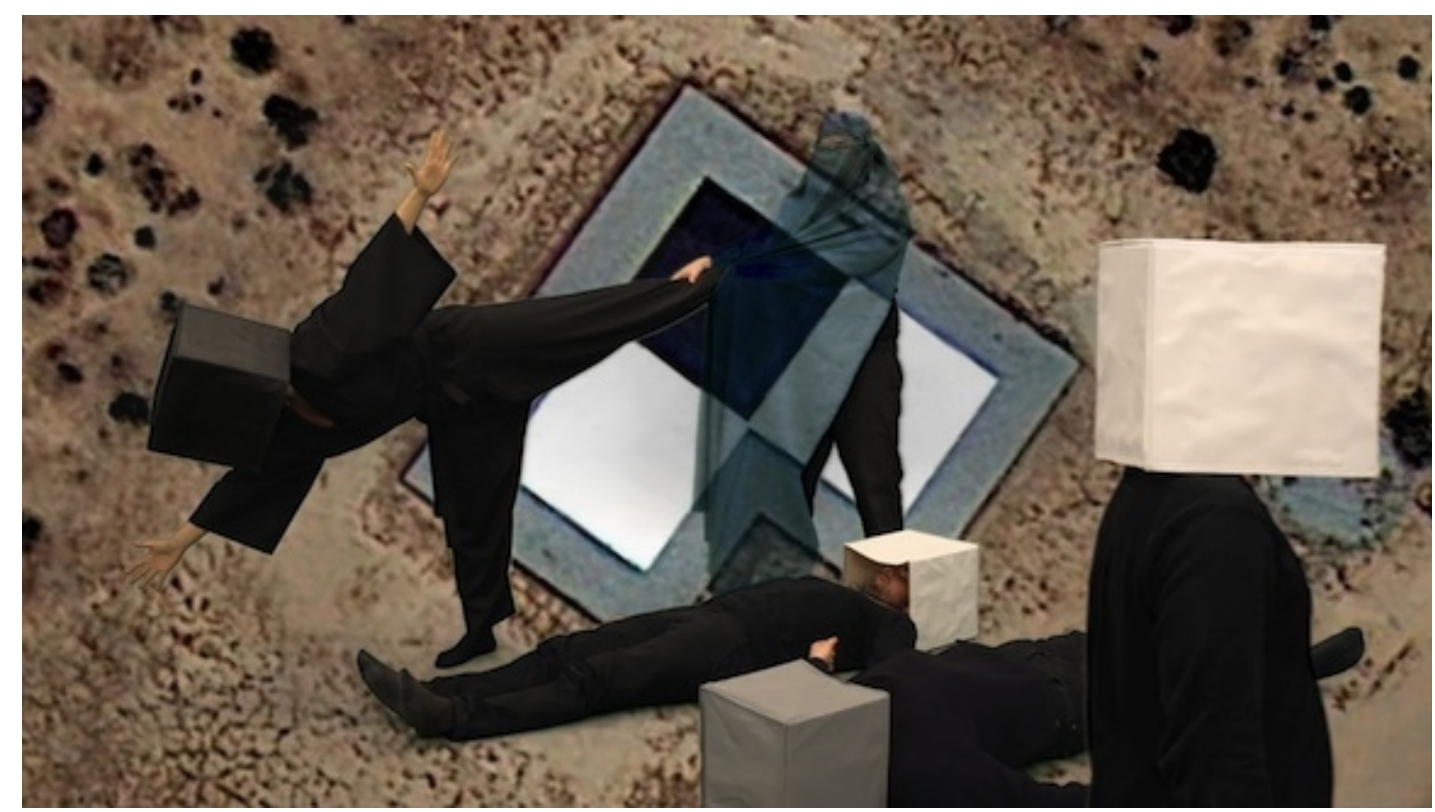

Captura de pantalla del vídeo How Not to be Seen: A Fucking Didactic Educational.MOV File (Steyerl, 2013). Fuente: Rhizome Journal, (2013). <http://rhizome.org/editorial/2013/may/31/hito-steyerl-how-not-to-beseen/>.

La identidad digital puede ser definida como un lazo tecnológico entre una entidad real - persona, organismo o empresa - y una entidad virtual - su representación o representaciones digitales (Identité numérique, s.f). Fanny Georges (2008) habla de "hexis digital" como una escultura de uno mismo que opera en el mundo virtual. En todo caso, el concepto se halla li gado a nuestras acciones en entornos digitales, a nuestros avatares y perfiles en línea, a la información que compartimos en nuestras redes sociales, a los datos derivados de nuestros objetos digitales personales, etc. En su obra, Georges la divide en tres dimensiones: la identidad declarativa: lo que expresa directamente el usuario; la identidad operante: resultado de las actividades y hábitos en línea; la identidad calculada: producida por un tratamiento automático de los datos obtenidos de la identidad operativa.

Resulta evidente el nexo directo entre identidad digital e incremento de visibilidad. Ella supone el esparcimiento de una gran cantidad de datos personales que permiten escudriñar y 
seguir todos los movimientos de un individuo. De esta forma, el sujeto se convierte en una imagen de alta resolución.

\section{El punto de vista aéreo del poder. Posición desventajosa del sujeto vigilado}

La hipervisibilidad del sujeto, derivada de la proliferación de las máquinas de visión y de los procesos de datificación, le otorga al poder un punto de vista aéreo y despersonalizado. Aquí Steyerl señala aquello que constituye la bisagra en la evolución de los objetos técnicos digitales e Internet, a saber, mientras más visible y $H D$ se hace el usuario, más invisible se hace la tecnología y el poder ligado ella.

Como resultado de la automatización y la industrialización de la visión existen dos elementos a tener en cuenta, ya que generan condiciones favorables para ejercer la vigilancia y situar al sujeto en una posición desventajosa. Uno de ellos es el surgimiento de una capacidad de visión extremadamente aumentada y poderosa dado que supera las limitaciones corporales humanas. El otro es, la oportunidad de tener una visión despersonalizada que le permite al poder ejercer una mirada intrusiva sin hacerse responsable ni localizable como sujeto de dicha mirada.

Virilio afirma que asistimos a un desbordamiento del punto de vista humano. El autor ci tando a Merleau-Ponty, explica:

"Todo aquello que veo está en principio a mi alcance (al menos al alcance de mi mirada), sobre la premisa del "yo puedo". En esta frase importante, Merleau-Ponty describe aquello que se destruirá con la teletopología devenida corriente. En efecto, lo esencial de aquello que yo veo ya no se encuentra, en principio, a mi alcance por más que se encuentre al alcance de mi mirada, pues no se inscribe necesariamente bajo la premisa del "yo puedo"

(Virilio, 1988, pp. 26-27). ${ }^{3}$

La visión de la máquina permite superar la perspectiva ligada a una posición precisa del cuerpo y a una única línea de horizonte que organice el campo de visión en el espacio. En re-

\footnotetext{
${ }^{3}$ Trad. personal. Texto original: "Tout ce que je vois est par principe à ma portée (au moins à la portée de mon regard), relevé sur la carte du «je peux». Dans cette phrase importante, Merleau-Ponty décrit ce qui va se trouver ruiné par la télétopologie devenue ordinaire. L'essentiel de ce que je vois n'est plus, en effet, par principe, à ma por tée et même s'il se trouve à la portée de mon regard, il ne s'inscrit plus forcément sur la carte du «je peux»”.
} 
lación a la vigilancia, el hecho de delegar la construcción de la realidad objetiva a un objeto técnico provoca un delirio de persecución debido al desdoblamiento entre lo animado y lo inanimado. El poder, sirviéndose de la tecnología, obtiene un punto de vista panorámico global y logra pasar desapercibido.

En efecto, si aquél que ve es un objeto, entonces el poder que mira y se sirve de estas imágenes derivadas de una visión maquínica, ${ }^{4}$ puede ejercer a sus anchas la vigilancia sin ser localizado como "sujeto responsable" de ello. Se trata de una separación de "la visión" 5 del "acto de mirar": ${ }^{6}$ la máquina ve y recolecta aquello que el poder mira. Ella puede captar las cosas pero no puede, propiamente hablando, ejercer una "mirada" sobre ellas. La mirada supone al sujeto. Si es atenta o intrusiva es porque ya se le ha dado un valor, una utilidad o un objetivo preciso al acto de observación. El poder que ejerce la vigilancia se oculta detrás de la visión neutra de la máquina para permanecer invisible y no identificable.

Hito Steyerl decidió filmar este vídeo en un target de resolución precisamente, porque este lugar representa el punto de vista privilegiado del poder. Se trata de una mirada que flota, que está por doquier y en ningún parte. La artista la caracteriza como una "vista desde lo alto" que sirve para recrear sociedades en una lógica verticalista. En su artículo "The Wretched of the screen" afirma: "Las vistas aéreas recrean sociedades como abismos urbanos en caída libre y terrenos ocupados de forma desarticulada, a los que se los vigila aéreamente y se los controla biopolíticamente (...)"7 (Steyerl, 2012, p.14). El punto de vista aéreo y la mirada escindida del cuerpo poseen las características del ojo divino que todo lo ve, sin ser visto.

\footnotetext{
${ }^{4}$ Utilizamos el adjetivo "maquínico" y no "mecánico" porque este último no hace justicia a las características de los objetos de visión modernos. Estos ya no son simplemente mecánicos, sino que son máquinas informatizadas.

${ }^{5}$ Ver significa: "Percibir por los ojos los objetos mediante la acción de la luz". Ver. (2014). En Diccionario de la Real Academia Española.

${ }^{6}$ La definición de "mirar" es: "Dirigir la vista a un objeto"; y en sentido figurado esta palabra significa: "Inquirir, buscar algo, informarse de ello”. Mirar. (2014). En Diccionario de la Real Academia Española.

${ }^{7}$ Trad. personal. Texto original : "Views from above recreates societies as free-falling urban abasys and splintered terrains of occupation, surveilled aerially and policed biopollitically (...)"
} 


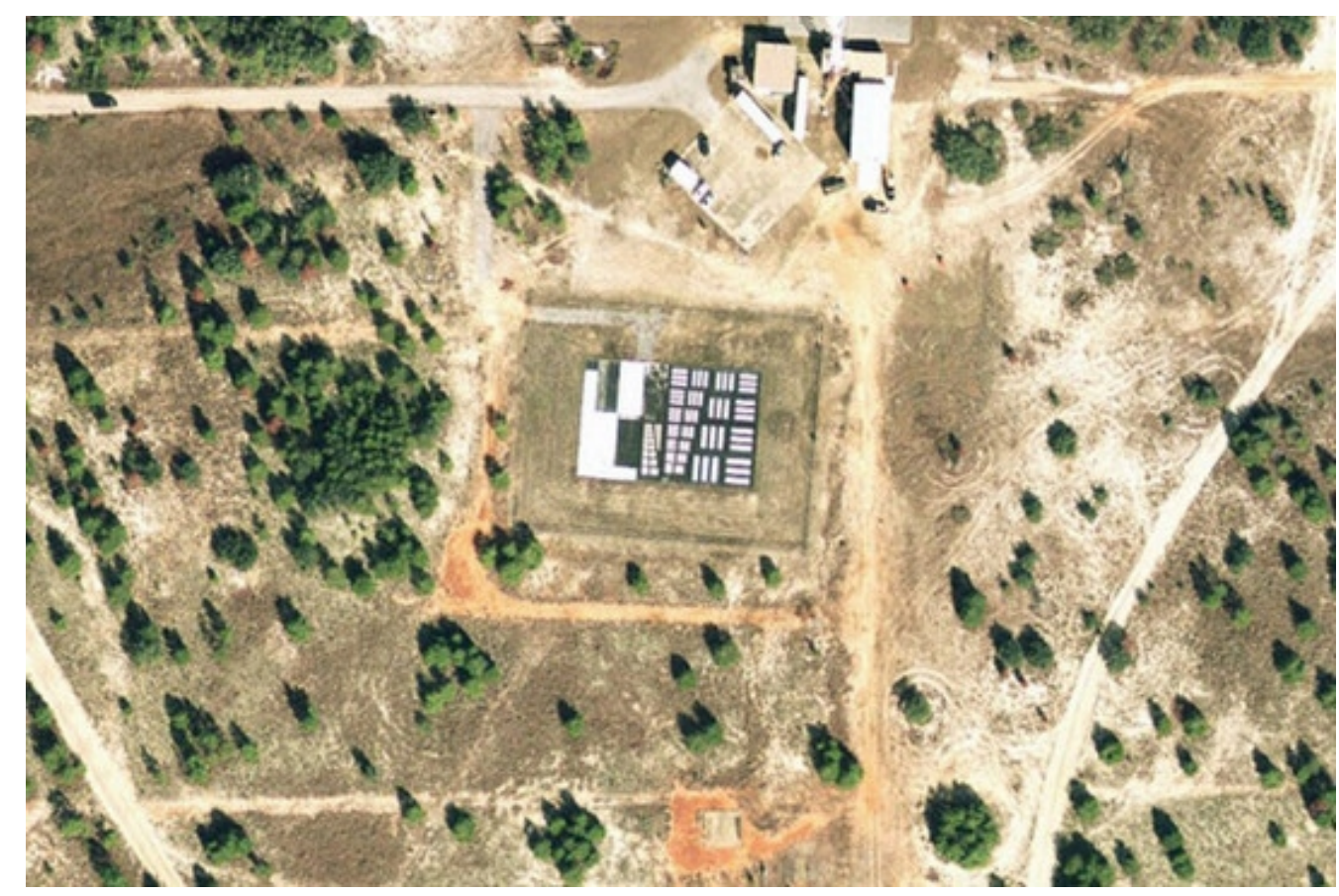

Captura de pantalla del vídeo How Not to be Seen: A Fucking Didactic Educational.MOV File (Steyerl, 2013). Fuente: Svenska Fotografers Förbund. Rapport fran Vending. (2013). <http://sfoto.se/f/artiklar/rapportfran-venedig-2013>.

En este vídeo, la artista representa este punto de vista del poder a través del target de resolución aérea, como ya lo hemos dicho, pero también a través de las imágenes de animación 3D. En efecto, esta tecnología introdujo la posibilidad de generar vistas desde una perspectiva múltiple. Las partes de animación 3D vienen a ejemplificar esta capacidad de visión absoluta, multifocal y de perspectiva variable que hace posible el fenómeno de datificación y que caracteriza a la mirada sin límites de la data-vigilancia actual. 


\section{La fuente de las imágenes de vigilancia Posición ventajosa del sujeto vigilado}

How Not to be Seen: A Fucking Didactic Educational.MOV File juega constantemente con las ambigüedades y con las dos caras que tiene todo fenómeno. En efecto, la mirada intrusiva del poder en la era digital se dirige a imágenes cuya captación la realiza el mismo sujeto vigilado. La artista nos muestra, de este modo, como la posición, en principio desventajosa, del sujeto puede devenir ventajosa si éste toma conciencia y se asume como proveedor del poder que lo vigila y lo controla.

Contrariamente a la vigilancia tradicional, en la era digital cada sujeto se autocapta y se introduce en la red. Se trata de un cambio respecto al lugar de producción de las imágenes de vigilancia, de una autopóiesis de las mismas. Ya no se trata de un dispositivo externo, que se halla fuera de nuestro espacio íntimo, como podría serlo una cámara de vigilancia que se encuentra en la calle o en un establecimiento, que nos graba y provee estas imágenes a una institución, empresa o servicio de inteligencia. Hoy en día, la tendencia general en el uso de Internet promueve hábitos dirigidos a hacernos mostrar una importante cantidad de imágenes de nuestra vida privada y nuestra intimidad en la red. En Internet, la vigilancia ya no funciona como un Panóptico, como una máquina de visión, sino como una máquina de recolección. Esta máquina recolecta las imágenes y los datos que ya están disponibles en la web. Por ello, para limitar y controlar la mirada que el poder se hará de nosotros es necesario prever qué tipo de imágenes vamos a sembrar en la red.

Hito Steyerl desplaza la atención desde la vigilancia hacia las condiciones de posibilidad y el proceso de constitución de la misma. Como DeLa (1971) de Michael Snow, que desplaza la atención de las imágenes al dispositivo que permite producirlas, Hito Steyerl también muestra en How not to be seen el dispositivo con el que ha sido filmado el vídeo. Se trata de un intento de educar al espectador a mirar detrás de la pantalla, al lugar donde se generan las imágenes.

Desde hace algunos años, las prácticas en línea han instaurado un régimen de difusión de sí mismo. La presencia distribuida del sujeto en Internet se realiza a través de un flujo de imá genes que nosotros mismos introducimos, y una vez allí se dispersan en todas las direcciones sin que podamos controlar su destino final. Las imágenes se vuelven independientes y autónomas y el sujeto no puede prever el uso que harán de ellas otras personas, empresas o instituciones. 
Resulta cada vez más habitual registrar todos los momentos de nuestra vida, ya sea en foto o en vídeo, y compartirlos en las redes sociales. Disponemos en permanencia de una cámara en nuestros móviles y el uso que hacemos de ella ya no se haya ligado al hecho de guardar en una memoria visual momentos especiales. Producimos imágenes de las cosas más banales, que no tienen nada de extraordinario. Fotografiamos el plato de comida de nuestro almuerzo, la posición en la que duerme nuestro gato, nuestra cara de recién despertados, nuestro camino al trabajo, en fin, "cualquier cosa". Sacar el móvil y tomar una fotografía hoy en día, más que un hábito, se ha vuelto un tic, un acto reflejo. Pero este "cualquier cosa" no es tal, y no es tan ino cente, estas "cosas" conforman los fragmentos de nuestra vida privada. Subiendo estas imágenes estamos informando: el tipo de alimentos que consumimos, cuál es nuestro gato, cuál es la línea de metro que tomamos para ir al trabajo, a qué hora nos despertamos, etc.

De tal modo que, este flujo de imágenes, que en principio estaban destinadas seguramente a ser compartidas únicamente con amigos, puede eventualmente transformarse en la fuente de nuestra vigilancia y del poder que se ejerce sobre nosotros. Por la simple razón de que no podemos controlar el destino final de la imagen digital ya no reparamos en el beneficio que puede sacar otra persona, servicio de inteligencia o empresario de esta documentación voluntaria de nuestras vidas.

No en vano, Hito Steyerl titula su video fucking didactic educational.MOV file. Se trata de un documento educativo que intenta instruir al espectador a fin de enseñarle a controlar su vi sibilidad, de hacerle tomar conciencia que las imágenes que él sube a Internet delimitarán hasta dónde podrá ser vigilado y en ese sentido, hasta dónde será susceptible de ser o no objeto de control. La artista parece querernos hacer comprender que ser los suministradores de estas imágenes nos pone en una situación desventajosa y ventajosa a la vez, de peligro y de poder. Tomando conciencia de nuestra contribución a la vigilancia y responsabilizándonos de ello, podemos tomar las riendas del poder que le entregamos al poder.

La vigilancia ya está allí, instaurada en el régimen de hipervisibilidad que ha fundado la industria de máquinas de visión y los procesos de datificación. Pera protegernos, debemos confundirla y contrariarla aprendiendo a gestionar nuestra visibilidad. Esta obra pone de manifiesto la necesidad de informar y educar a las personas para que sean capaces de defenderse de los modos de vigilancia y control actuales. 


\section{Lecciones de invisibilidad}

En correspondencia con esta necesidad de educación e instrucción, Hito Steyerl presenta tác ticas, a primera vista naifs y absurdas, pero en efecto, muy concretas y realistas. La primera de estas lecciones nos enseña "cómo hacer algo invisible para una cámara". La misma comienza por la premisa de "esconderse". En ese instante vemos el target de resolución a pequeña escala, lo cual nos anuncia que la clave para esconder algo ante una cámara está en su resolución. Luego, vemos la imagen de la artista desenfocarse cada vez más hasta quedar bo rrosa y pixelada. Hito Steyerl nos invita a servirnos de las imágenes de baja resolución, a salir de la lógica de la high tech y la high definition, a no ir a la misma velocidad que impone la evolución tecnológica.

Figura 5: Píxeles LUCHANDO FRENTE AL TARGET DE RESOLUCIÓN

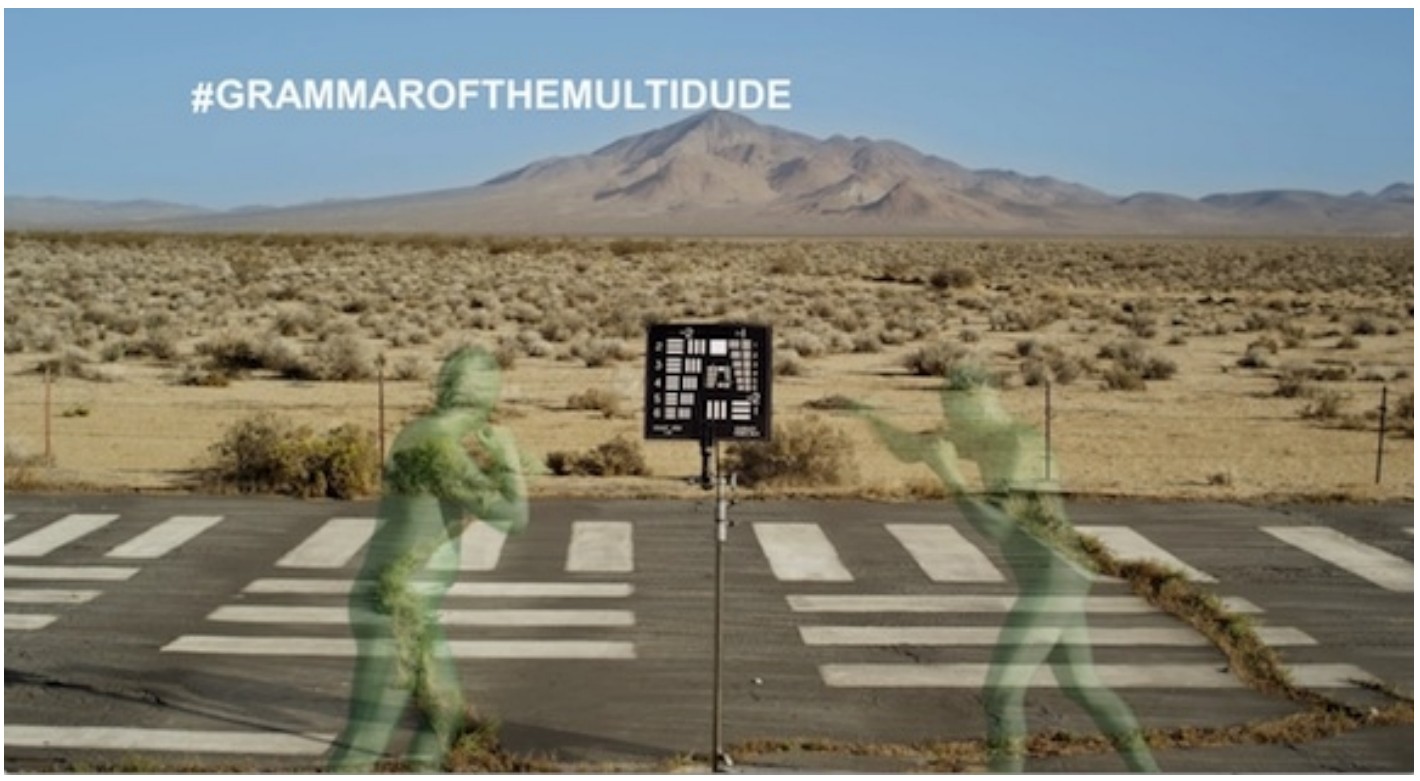

Captura de pantalla del vídeo How Not to be Seen: A Fucking Didactic Educational.MOV File (Steyerl, 2013).

Fuente: Rhizome Journal (2013). <http://rhizome.org/editorial/2013/may/31/hito-steyerl-how-not-to-beseen/>. 
Si la identidad del sujeto es medida en términos de resolución, entonces, el mejor modo de de fenderse de la vigilancia pasa por las imágenes en baja resolución. En la lección cinco se nos informa que el target californiano servía para medir un tipo de resolución hoy en día obsoleta, aquella de las cámaras analógicas. La artista nos invita a pensar que la resolución obsoleta puede convertirse en un escudo para defendernos. En este target abandonado, habitan píxeles de baja resolución. Éstos aparecen representados como figuras humanas semi-transparentes, el sujeto de baja resolución logra ser, efectivamente, más invisible.

La artista defiende así, aquello que ella denomina "la imagen pobre":

La imagen pobre es un golpecito o un rasguño, un AVI o un JPEG, un lumpen proletariado en la clase social de las apariencias, considerado y valorado según su resolución (...) El estar en foco se identifica con una posición de clase, una posición de facilidad y privilegio, mientras que estar fuera de foco baja el valor de uno mismo en cuanto imagen. La jerarquía contemporánea de las imágenes, sin embargo, no sólo está basada en su definición, sino también y primordialmente en su resolución. (...) Obviamente una imagen de alta resolución resulta más brillante, más mimética y mágica, más aterradora y seductora que una imagen pobre. Es, por así decirlo, más rica. ${ }^{8}$

(Steyerl, 2012, p.17).

La imagen pobre nos permite no dejar una huella tan clara de nosotros mismos, no construir una imagen detallada y cargada de información relevante. De esta forma, nos ofrece la posibilidad de no ser un blanco fácil y descifrable ante el poder. Por estas razones, la misma es celebrada por la artista y defendida como modo de escapatoria al asedio de la ciber-vigilancia.

Las tácticas que siguen a esta lección son: quitarse del medio, salir de la pantalla y desaparecer. Debemos frenar nuestro frenesí por fotografiar y fotografiarnos, salirnos del campo de visión de las máquinas de visión. En clara referencia a la constante y excesiva autocaptación óptica (selfies) y registro de nuestro entorno, la artista nos invita a un gesto tan básico y simple como la abstención: dejar de tomar tantas fotos. Es preciso controlar y educar el hábito que

\footnotetext{
${ }^{8}$ Trad. personal. Text original: "The poor image is a rap or a rip, an AVI or a JPEG, a lumpen proletariat in the class society of appearances, ranked and valued according to its resolution (...) Focus is identified with a class position, a position of ease and privilege, while being out of focus lowers own value as an image. The contemporary hierarchy of images, however, is not only based on sharpness, but also and primarily in resolution. (...) Obviously a high-resolution image looks more brilliant, more mimetic and magic, more scary and seductive than a poor one. It is more rich, so to speak".
} 
nos mueve a querer registrar absolutamente todo. Debemos dejar de ser el blanco del objetivo de la cámara y aprender a permanecer fuera de la pantalla (to go offscreen).

La segunda lección se titula How to be invisible in plain sight. La escena comienza con la figura de la artista vestida de ninja y la imagen del target de resolución de fondo. Dicha lección nos presenta ante una situación radical: nos hallamos en un régimen de visibilidad extremo y somos un blanco fácil. La figura del target es extremadamente importante en esta obra, pues ella nos da la clave de lo que caracteriza las modalidades de vigilancia en la era di gital: la posibilidad de rastrear y localizar a alguien en sólo algunos segundos. Es necesario tomar conciencia de que nuestras imágenes hablan y eso que dicen, más allá de lo que muestran, son los "metadatos". Datos derivados de nuestro IP, nuestra geolocalización, nuestro número de móvil asociado a nuestros correos electrónicos, perfiles en las redes sociales, contactos, tarjetas de crédito, etc.

Por ello, debemos actuar como ninjas, calcular nuestros movimientos y nuestra autodifusión de imágenes. Hito Steyerl parece empujarnos a no dejarnos llevar por la actitud despreocupada y naif que tiende a mostrarlo todo y nos recuerda: "Hoy en día las cosas más importantes quieren seguir siendo invisibles. El amor es invisible, la guerra es invisible, el capitalismo es invisible". 9

La tercera lección lleva por título How to become invisible by becoming a picture. El título ya nos indica que es imposible escapar completamente al régimen de visibilidad. El sujeto y el mundo se han transformado en imágenes. En esta parte del vídeo se desarrollan una serie de tácticas que, en lugar de buscar la absoluta invisibilidad, proponen formas de visibilidad que confunden y desorienten. El objetivo es encontrar la plasticidad de las imágenes que produ cimos. Estas tácticas son del orden del "camuflaje", del "disfraz" y del "enmascaramiento". En síntesis, todas ellas resumen formas de engañar la mirada de la vigilancia, de salir de la lógica de la transparencia, de despistar y desconcertar al poder. En un gesto que nos recuerda a aquél de Peter Campus en Three transitions (1973), la artista camufla su rostro utilizando la técnica del chroma key. Recubriendo partes de su cara con pintura verde, su rostro se mezcla con diversas imágenes que se superponen. Esta lección termina diciéndonos que es imposible alcanzar la completa invisibilidad porque para ello sería necesario devenir más pequeño que un pixel.

\footnotetext{
${ }^{9}$ Trad. personal. Texto original: "Today most important things want to remain invisible. Love is invisible, war is invisible, capitalism is invisible".
} 
En nuestra época, salirse por completo del régimen de visibilidad tiene un lado oscuro, puede significar la real y concreta desaparición de una persona. Así, encadena la próxima lec ción cuyo título es How to remain invisible by disappearing. Cuando se le preguntó a la artista en una entrevista sobre este deseo de desaparición, remarcó que se trata de un concepto muy ambivalente. Por un lado, es algo muy deseable que nos alivia del constante reflejo de nosotros mismos por las imágenes, propio de nuestra época y que toca a todo el mundo; pero, por otro lado, debería darnos miedo si tenemos en cuenta que la misma puede ser utilizada como forma de abducción política (Connor, 2013).

La invisibilidad no quiere decir "no estar ahí", sino simplemente "no ser visible"; pero cuando le quitamos visibilidad al sujeto contemporáneo, ¿qué es lo que queda de él? Si nos hallamos en un abusivo régimen de visibilidad, entonces ser completamente invisible quiere decir "no estar más allí", haber sido eliminado, erradicado. La última táctica pronunciada en esta lección es "ser una persona desaparecida, como un enemigo del Estado que ha sido elimi nado, liquidado y luego disimulado". Esto hace referencia, claramente, a su amiga Andrea Wolf, una militante del PKK (Partido Karkerani Kurdistan), desaparecida desde 1998. Esta mujer comprometida con la causa kurda desapareció de un día para otro. Hito Steyerl afirma que nadie ha hecho ningún esfuerzo por clarificar el hecho, aquí no hubo medios de comuni cación, periodistas, imágenes ni fotos (Kunak, 2013). Su amiga ha sido víctima del reverso oscuro de la invisibilidad. El asunto de Andrea Wolf es un tema recurrente en la obra de la artista. Ha sido el tema de sus vídeos November (2004), Lovely Andrea (2007) y Abstract (2012).

Al final del vídeo, vemos sobre el desierto californiano una especie de biombo que funciona como pantalla donde se proyectan imágenes en 3D. Se trata de palomas blancas y figuras humanas que, de pronto, salen de los límites de la pantalla y se incorporan a la realidad física. La superabundancia de imágenes en el mundo virtual más que tener un "efecto de realidad", detenta la realidad. Ellas reestructuran el mundo físico y tienen efectos concretos sobre las personas. Esto resulta evidente, por ejemplo, cuando vemos a los actores someterse a una gran cantidad de cirugías estéticas para hacer coincidir su imagen física con su imagen mediática.

El poder económico y político parece haber comprendido que la manera más eficaz de di rigir el comportamiento y las inclinaciones humanas, no es sacar a las imágenes del estatus de pobreza ontológica al que Platón las había relegado y hacerlas igual de reales que nosotros mismos, sino invertir los términos de la dicotomía. El control se ejerce respetando el modelo tradicional entre realidad y representación, pero alterando los roles. Hoy en día, son las imágenes las encargadas de presentar la realidad que el sujeto debe representar. Se trata de un 
modus ponens, de una inversión lógica. Si poseemos un modelo de visibilidad en donde la imagen representa la realidad, ¿por qué no imponer uno en el que la realidad represente a la imagen? Evidentemente, construir imágenes para ejercer el poder y el control, resulta mucho más fácil que construir realidades.

Figura 6: LaS IMÁGENES SALEN DE LA PANTALLA

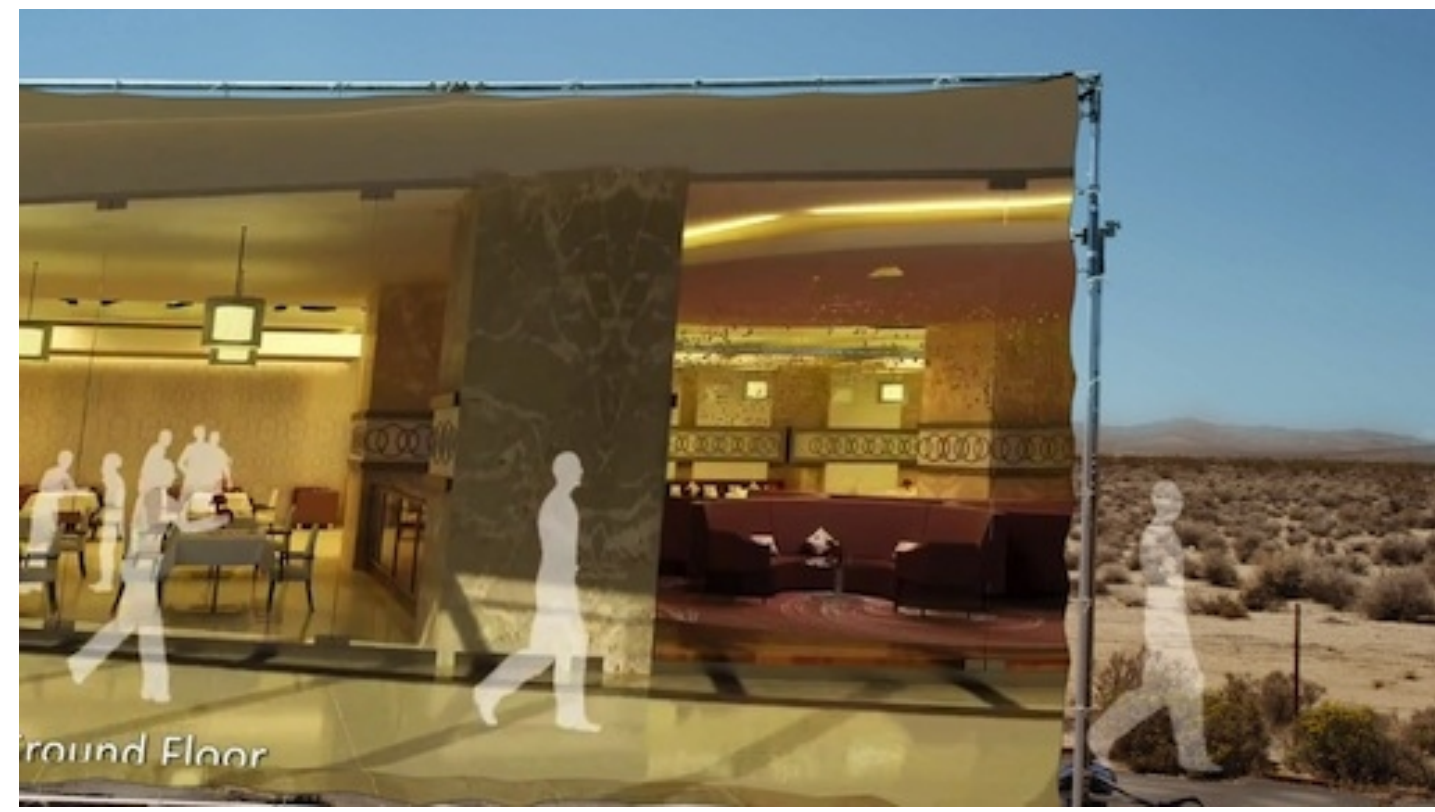

Captura de pantalla del vídeo How Not to be Seen: A Fucking Didactic Educational.MOV File (Steyerl, 2013).

Fuente: Verifica Incerta Magazine. <http://www.verificaincerta.it/chi-ha-visto-come-non-essere-visto/>.

\section{Las nuevas modalidades de vigilancia}

Resulta difícil definir el concepto de vigilancia porque ella se define en gran medida por el dispositivo con el que se realice en cada caso. Sin embargo podemos afirmar que tiene que ver con una observación atenta y examinadora que busca ejercer un control.

El dispositivo por excelencia para hablar de vigilancia ha sido el del Panóptico de Bentham propuesto por Foucault en Vigilar y Castigar (1974). Este modelo de vigilancia ha resultado especialmente eficaz para explicar las formas de control propias de las sociedades disciplina- 
rias del siglo XIII y XIX. El Panóptico consiste en un modelo de prisión en donde, desde un anillo central, se pueden controlar todas las celdas. Esta arquitectura de vigilancia permite reforzar el comportamiento y la homogeneización de los individuos al hacerlos sentirse observados en permanencia. Françoise Parfait explica: "Cada prisionero, sabiendo que puede ser visto en permanencia, asegura el funcionamiento del poder, sin que haga falta que ninguna persona tenga que asumir esta tarea" (Parfait, 2001, p.278) .

Sin embargo, numerosos teóricos coinciden en el hecho de que este modelo ya no resulta adecuado para dar cuenta de las nuevas formas de vigilancia que se han surgido en el siglo XX y en el XXI y que es necesario proponer modelos post-panópticos (Boyle, 2010). En esta línea, Zygmunt Bauman (1999) propone el modelo del sinóptico de Thomas Mathiesen (1997). Este último se corresponde con las nuevas formas líquidas, flexibles y deterritorializadas que exigen la economía globalizada y la sociedad de consumo.

Es decir, al dispositivo sinóptico no le interesa la producción de una fuerza de trabajo dócil y útil, sino la elaboración de un sujeto espectador, o lo que es lo mismo, la producción de consumidores. Esto lo hace mediante la difusión y legitimación comunicacional de un estilo de vida y gracias a la proliferación incesante de la diversidad como rasgo principal de la cultura tardo-moderna.

(Castro Orellana, 2008, p.350)

Si en el panóptico unos pocos observaban a muchos para ejercer el poder, en el sinóptico son muchos los que observan a unos pocos, a través de los medios masivos de comunicación. De esta forma, los individuos/espectadores reproducen los códigos que el poder difunde.

Sin embargo, Internet, la web participativa y las redes sociales ha traído un nuevo modelo de vigilancia más horizontal que podría caracterizarse de anfisinóptico, ${ }^{10}$ un modelo en el que todos se miran mutuamente, y que genera sin duda, una sociedad en la que los lazos sociales están cada vez más marcados por la competitividad y el narcisismo. Como afirma Gary T. Marx (2005) la vigilancia tradicional implicaba una clara distinción entre el sujeto observado y el agente que ejercía la mirada. Sin embargo, en la "nueva vigilancia" que se caracteriza por formas de auto-vigilancia, vigilancia cooperativa y exposición voluntaria, la distinción entre el agente y el sujeto de la vigilancia es difícil de establecer.

\footnotetext{
${ }^{10}$ El prefijo "anfi" en griego significa: a ambos lados.
} 
Hoy en día ya no son sólo las celebrities las que gozan de visibilidad mediática, la identidad digital ha traído aparejada una sur-visibilidad generalizada. En este sentido, el motto de Youtube resulta elocuente: "Broadcast yourself".

Cabe preguntarnos entonces si estas nuevas formas de vigilancia implican la eliminación de los demás modelos que poseen una arquitectura jerárquica y que funcionan con una dinámica de arriba-abajo. Sin duda, la exposición voluntaria de la vida privada del sujeto en línea genera que se instalen hábitos de anfivigilancia horizontales. Sin embargo, estas formas coexisten con formas de vigilancia jerárquicas de alcance global.

La cibervigilancia sigue estando estrechamente ligada al poder político y económico. Se trata de una estructura de poder donde son las grandes corporaciones que manejan Internet las que se encuentran a la cabeza, pues ellas son las que detentan los grandes centros de datos que recopilan la información derivada de la identidad digital declarativa, operativa y calculada. Hablamos del oligopolio que representan empresas como Google, Facebook, Microsoft, Twitter, Telefónica y Yahoo. Estas coorporaciones generan valor y capitalizan los datos producidos por las identidades digitales. Luego esta información puede ser vendida a diferentes empresas de minería de datos para realizar, por ejemplo, publicidades dirigidas. Un tipo de marketing donde ya se conoce el receptor del mensaje y que por ello resulta mucho más efectiva que la publicidad tradicional. En este sentido, la cibervigilancia sigue manteniendo una estructura jerárquica y verticalista que contribuye a reproducir sujetos consumistas.

Asimismo, resulta claro como los sistemas de vigilancia masivos basados en la tecnología pueden ser provechosos para fines de control y competencia política; el caso Snowden lo puso en evidencia. Aquí también nos encontramos con una estructura jerárquica, donde no sólo el individuo se ve indefenso ante el poder político, a su vez, ciertos estados con menos desarrollo e infraestructura tecnológica se encuentran indefensos frente al poder de otros estados altamente tecnologizados.

\section{Actualización de la noción de "privacidad"}

Dada la hipervisibilidad que caracteriza a nuestro contexto socio-técnico, muchos autores de claran que la privacidad ya no puede ser el horizonte desde el cual se deben tratar los problemas de vigilancia. Mark Poster (1990) afirma que "las líneas que separan a los individuos entre sí y a los individuos de las instituciones se hallan constantemente atravesadas por 
bases de datos computarizadas, cancelando así la privacidad como un modelo de acción o incluso como un problema"11 ( como se cita en Sevignani, 2015, 142).

Calvin Gotlieb hace una diferenciación entre los conceptos de "privacidad", "confidencialidad" y "seguridad". La privacidad es un concepto social, cultural y legal que varía de un país a otro. La confidencialidad se refiere a la responsabilidad y las reglas para la gestión de los datos. La seguridad concierne a la infraestructura técnica que se debe utilizar para que las reglas de confidencialidad sean satisfactorias. A partir de esta clasificación, el autor defiende que es un error poner el énfasis en la privacidad porque la mayoría de las veces, cuando existen ciertos beneficios, a la gente no le interesa sacrificar su privacidad. Su tesis es que "las compensaciones recíprocas en las que la privacidad ha sido sacrificada son tan comunes que, para cualquier objetivo práctico, la privacidad ya no existe" ${ }^{12}$ (Gotlieb, 1996, p. 156). El autor propone entonces, concentrarse en los conceptos de confidencialidad y de seguridad, es decir, en los aspectos más bien técnicos. La ley, la parte social y cultural no deberían ser el foco de la discusión en torno a la vigilancia.

Resulta evidente que la noción de privacidad tal como se ha entendido tradicionalmente debe ser revisada, sin embargo, ello no implica que tengamos que dejarla fuera de la discusión. Consideramos que hoy más que nunca necesitamos incluir la parte social, cultural y legal en la discusión sobre la vigilancia.

Somos la primera generación de las tecnologías digitales e Internet, tecnologías que ha revolucionado la vida en todos sus aspectos y que utilizamos sin terminar de saber cómo funcionan. Ante ciertos aspectos técnicos nos encontramos ciegos. Como afirma Bernard Stiegler:

Hoy necesitamos comprender el proceso de evolución técnica ya que experimentamos una considerable opacidad de la técnica contemporánea: no comprendemos inmediatamente aquello que está realmente en juego y que se transforma en profundidad, aunque tengamos constantemente que tomar al respecto decisiones cuyas consecuencias tenemos cada vez más la sensación de no controlar.

(Stiegler, 2002, p. 41).

\footnotetext{
${ }^{11}$ Trad. personal. Texto original: "The line dividing individual from individual and individual from institution are constantly crossed by computer databases cancelling privacy as a model of action or even as an issue".

12 Trad. personal. Texto original: "The thesis of this presentation is that the trade-offs when privacy has been sacrificed, are now so common that, for all practical purpose, privacy no longer exist"
} 
Si no queremos quedar a merced del poder tecnocrático es preciso poner el énfasis en la edu cación para empoderar a los individuos y generar usos y hábitos que nos beneficien a todos. El vídeo de Hito Steyerl, se encuentra en correspondencia con esta necesidad.

Sin embargo, las técnicas propuestas por la artista para alcanzar la invisibilidad no resultan del todo resolutivas. Es preciso asumir que la identidad digital viene asociada a un necesario e inevitable incremento de visibilidad. Pero ésta no es sinónimo de vigilancia, el pasaje de una a la otra implica una hermenéutica de lo visible, es decir, una manera precisa de interpretarlo.

Por ello, proponemos en este artículo que no debemos renunciar a hablar de "privacidad" en la discusión en torno a la vigilancia, sino que debemos repensar este concepto articulándolo con el concepto de identidad digital.

La privacidad no implica necesariamente la invisibilidad, sino algo que nosotros decidimos compartir consciente y voluntariamente con ciertas personas y con otras no. Se habla así, por ejemplo, de un asunto privado de la familia, o de una charla privada con un amigo. En este sentido la privacidad tiene que ver directamente con el poder que un individuo tiene para ges tionar la visibilidad que genera su propia identidad. Es decir, la capacidad de control que uno tiene sobre todo aquello que exterioriza y que, en ciertos casos, deja huellas.

Lo importante es que en el ámbito social, e Internet lo es, el sujeto pueda seguir teniendo la posibilidad de elegir con quien quiere compartir o no sus ideas, sus gustos, sus inclinaciones. Es cierto que, en general, debemos aceptar las condiciones de uso, sin embargo, estos documentos suelen ser largos en exceso y engorrosos a leer lo que hace que la mayoría de las personas los pasen por alto. Además no dan cuenta del uso concreto que se hará en cada caso. Que las empresas pongan sus condiciones, no resulta una manera justa ni equitativa de resolver la situación.

Sin duda las personas quieren voluntariamente ser más públicas en el siglo XXI, quieren compartir y conectarse más. Pero al compartir sus emociones o pensamientos en las redes sociales no están dando su consentimiento a que esto sea luego vendido. En principio, la intención es simplemente compartirlo con sus contactos.

Como afirma Gotlieb, el problema sí tiene que ver directamente con la reglas de gestión y confidencialidad de los datos, sin embargo estas esferas no deben separarse de la noción de privacidad en su aspecto social, cultural y legal. 


\section{La identidad digital y la I-Data potestad}

Para el asunto de la vigilancia sea tratado con igualdad de condiciones y de manera más equi tativa es necesario que se comience a hablar en el marco legal, ya no sólo de privacidad en el sentido tradicional, sino de los "derechos de las identidades digitales".

La identidad contemporánea está fuertemente marcada por los procesos de datificación. A nuestra presencia física y actual se le suma una presencia ubicua bajo la forma datos. Este cuerpo de datos no sólo dice lo que somos, o lo que hemos sido (cómo hemos actuado, nos hemos manifestado o exteriorizado en el pasado) sino que también determina en gran medida lo que seremos. Esa proyección hacia el futuro se realiza conforme a los criterios interpretativos que le apliquemos a ese cuerpo de datos.

Como explica Gilbert Simondon (1964), el individuo no es algo estable y cerrado en sí mismo, sino un proceso en constante individuación que funciona bajo dinámicas intermitentes de apertura y clausura a su medio asociado. El tratamiento que le demos a los datos reestructura nuestra realidad ya que genera las condiciones que conforman nuestro medio asociado.

La identidad digital es sumamente plástica, pues ella da un sinfín de posibilidades de lecturas diferentes. La decisión de lo que queremos devenir no puede estar sólo en manos de grandes corporaciones que manejan criterios exclusivamente mercantilistas.

Así como existen derechos relativos a nuestro cuerpo, deberíamos comenzar a pensar en derechos que nos garanticen potestad sobre nuestro cuerpo de datos, nuestro I-Data. Esto implicaría que los usos y condiciones de las plataformas, páginas web, redes sociales, buscadores de Internet, deberían formularse atendiendo a criterios de privacidad actualizados que se esta blezcan conforme a la defensa de la autonomía de las identidades digitales. 


\section{Referencias}

Bauman, Z. (1999). La globalización: consecuencias humanas. México: Fondo de Cultura Económica.

Boyle, R. (2000). Post-Panopticism, Economy and Society, 29, 2, 285-307.

Castro Orellana, R. (2008). Foucault y el cuidado de la libertad. Ética para un rostro de arena. Santiago: LOM Ediciones.

Connor, M. (31 de mayo 2013). Hito Steyerl's "How Not to be Seen: A Fucking Didactic Educational .MOV File". Rhizome Journal, 31. Recuperado de: <http://rhizome.org/editorial/2013/may/31/hito-steyerl-how-not-to-be-seen/>

De Certau, M. (1990). L’invention du quotidien, I: Arts de faire. Paris: Gallimard.

Diccionario de la Real Academia Española en línea (2014).

Duguet, A.M. (1988). Dispositifs. Communications, 48, 221-240.

Foucault, M. (2009). Surveiller et punir. Naissance de la prison. Saint-Armand, Francia: Editions Gallimard (Edición original 1975).

Gotlieb, C.C.(1996). Privacy: A Concept Whose Time has Come and Gone. En P.M, Regan, J.A Perrolle, A. Mauswhowitz, R. Kling, J.P Allen, O.H. Grandy, C.C. Gotlieb, M. Poster, G.T Marx, C.J. Bennett y S.G Davies, Computers, Surveillance, and Privacy (pp.156-171). Minneapolis/London: University of Minnesota Press.

IDENTITÉ NUMÉRIQUe (Internet). (s.f.) En Wikipedia. Recuperado el 16 de Noviembre de 2015 de: $<$ https://fr.wikipedia.org/wiki/Identit\%C3\%A9_num\%C3\%A9rique_(Internet)>

KunaK, G. (19 de noviembre de 2013). Interview // Hito Steyerl: Zero Probability and the Age of Mass Art Production. Berlin Art Link.

MARX, G.T. (2005). Surveillance and Society, Encyclopedia of Social Theory. Recuperado de: $<$ http://web.mit.edu/gtmarx/www/surandsoc.html - reading>

Mathiesen, T. (1997). The viewer society: Michel Foucault's "Panopticon" revisited. Theoretical Criminology: an international journal, 1 (2), 215-232.

Parfait, F. (2001). Vidéo. Un art contemporain. Paris: Editions du Regard.

Poster, M.(2004). The Information Empire, Comparative Literature Studies, 41, 3, 317-334. $<$ https://muse.jhu.edu/login? auth=0\&type=summary\&url=/journals/comparative_literature_studies/v041/41.3poster.html > 
Poster, M.(1990). The Modes of Information: Poststructuralism and Social Context. Cambridge: Polity Press.

Simondon, G.(1964). L’individuation à la lumière des notions de forme et d'information. París: Press Universitaires.

Sevignani, S. (2015). Privacy and Capitalism in the Age of Social Media. New York: Routledge.

Steyerl, H. (2013). Las imágenes salen de la pantalla. [Captura de pantalla de How Not To Be Seen: A Fucking Didactic Educational .MOV File]. Recuperado de: $<$ http://www.verificaincerta.it/chi-ha-visto-come-non-essere-visto/>

Steyerl, H. (2013). Personas representado píxeles. [Captura de pantalla de How Not To Be Seen: A Fucking Didactic Educational .MOV File]. Recuperado de: <http://rhizome.org/editorial/2013/may/31/hito-steyerl-how-not-to-be-seen/>

Steyerl, H. (2013). Píxeles luchando frente al target de resolución. [Captura de pantalla de How Not To Be Seen: A Fucking Didactic Educational .MOV File]. Recuperado de: $<$ http://rhizome.org/editorial/2013/may/31/hito-steyerl-how-not-to-be-seen/>

SteYerl, H. (2013). Soy completamente invisible. [Captura de pantalla de How Not To Be Seen: A Fucking Didactic Educational .MOV File]. Recuperado de: $<$ http://dismagazine.com/disillusioned-2/62143/hito-steyerl-politics-of-post-representation/>

SteYerl, H. (2012). The Wretched of the screen. E-flux, 14. Recuperado de: $<$ http://indexofpotential.net/uploads/46385/Steyerl,\%20Hito\%20-\%20The\%20Wretched $\% 20$ of $\% 20$ the $\% 20$ Screen.pdf $>$

SteYerl, H. (2013). Transformar el mundo en imagen. [Captura de pantalla de How Not To Be Seen: A Fucking Didactic Educational .MOV File]. Recuperado de: http://www.frieze.com/issue/article/the-film-essay/>

Steyerl, H. (2013). Vista aérea del target de resolución californiano. [Captura de pantalla de How Not To Be Seen: A Fucking Didactic Educational .MOV File]. Recuperado de: $<$ http://www.sfoto.se/f/artiklar/rapport-fran-venedig-2013>

Stiegler, B. (2004). De la misère symbolique I. L'époque hyperindustrielle. Paris: Editions Galilée. Stiegler, B. (2002). La técnica y el tiempo (Tomo I). Trad. por: Beatriz Morales Bastos. Hondarribia (Guipuzkoa): Cultura Libre (Edición original 1994).

VIRILIO, P. (1988). La machine de vision. Paris: Editions Galilée. 
